\title{
NEED FOR ACCREDITATION AGENCIES AS STAKEHOLDERS IN OPEN AND DISTANCE LEARNING: CASE OF "AUDAK" IN TURKISH HIGHER EDUCATION SYSTEM
}

\author{
Dr. Elif TOPRAK \\ ORCID: 0000-0002-4098-3676 \\ Open Education Faculty \\ Anadolu University \\ Eskisehir, TURKEY \\ Dr. Asuman Nurhan SAKAR \\ ORCID: 0000-0003-0444-279X \\ Open Education Faculty \\ Anadolu University \\ Eskisehir, TURKEY
}

Received: 11/09/2019 Accepted: 14/05/2020

\begin{abstract}
Accreditation agencies are important stakeholders for higher education institutions (HEIs) on the path to quality. They are advisors to suggest the appropriate models and tools for Quality Assurance (QA), according to the mode of delivery and institutional context. This paper gives brief history about integration of Turkey to Bologna process that has shaped the quality approach in the Turkish Higher Education System and explains how national accreditation agencies act to enhance quality in higher education. Secondly, a short literature on quality assurance in open and distance learning is provided with concentration on external evaluation by agencies. The transition to distance learning and e-learning more specifically, offers an opportunity to reorganize institutions for technology enhanced learning and enrich their means for quality assurance. Thirdly, the interpretation of European Standards and Guidelines for Quality Assurance in the European Higher Education Area (ESG 2015) for quality assurance in distance learning/e-learning and the adaptation of accreditation criteria to monitor compliance with pre-determined learning outcomes is elaborated through different models and benchmarks. As case-study, a new association founded in Turkey, AUDAK (Association for Evaluation and Accreditation of Open and Distance Education Programs) is introduced and its standards are discussed with an eye to the related literature and recent developments in Turkish higher education system.
\end{abstract}

Keywords: Quality assurance, accreditation, Bologna process, ESG 2015, quality in higher education, quality in open and distance education, quality in distance learning, quality in e-learning.

\section{INTRODUCTION}

The scientific and technological advances and economic globalization have accelerated the restructuring of higher education systems. Internationalization and the environment conducive for collaboration has paved the way also for common frameworks to compare systems and find solutions to similar problems with the involvement of stakeholders. International organizations, governmental and non-governmental have joined as actors to develop a common understanding to quality issues in higher education (HE). European Standards and Guidelines for Quality Assurance in the European Higher Education Area is a good example for these efforts. Quality assurance (QA) is among these cooperative issue areas whereby societal engagement of higher education is realized through the engagement of internal and external stakeholders. QA is an embracing term that covers all policies, processes and actions to maintain and develop the quality of a higher education institution. It involves the staff (academic, administrative and technical), students (enrolled and graduated), employers, representatives of the sectors graduates are expected to be a work 
force for. The internal and external stakeholders are important to develop an internal quality system and improve it. As regards external quality assurance, accreditation agencies have become important actors to guide institutions in the implementation and sustainability of quality standards. Accreditation refers to a form of quality assessment which involves a yes/no decision and a special status granted to an institution or program (Toprak \& Sakar, 2018). In the case of open and distance education, the role of accreditation agencies becomes even more critical since the interpretation, adaptation and adoption of standards designed for conventional education into distance learning is an area where there is need for professional assistance by Open and Distance Learning (ODL) specialists. Accreditation agencies are important stakeholders on the path to quality and are advisors to suggest the appropriate models and tools for QA, according to the mode of delivery and institutional context.

This paper gives brief history about integration of Turkey to Bologna process that has shaped the quality approach in the Turkish Higher Education System and explains how national accreditation agencies act as important stakeholders to enhance quality in higher education. Secondly, a short literature review on quality assurance in open and distance learning is provided with concentration on external evaluation by agencies. The transition to distance learning and e-learning more specifically, offers an opportunity to reorganize institutions for technology enhanced learning and enrich their means for quality assurance. Thirdly, the interpretation of European Standards and Guidelines for Quality Assurance in the European Higher Education Area (ESG 2015) for quality assurance in distance learning/e-learning and the adaptation of accreditation criteria to monitor compliance with pre-determined learning outcomes is elaborated through different models and benchmarks. As case-study, a new association founded in Turkey, AUDAK (Association for Evaluation and Accreditation of Open and Distance Education Programs) is introduced and its standards are discussed with an eye to the related literature and recent developments in Turkish higher education system.

\section{EFFECTS OF EUROPEAN STANDARDS AND GUIDELINES ON QUALITY ASSURANCE IN TURKISH HIGHER EDUCATION}

An example for extensive cooperation in transnational education, has been the Bologna Process, that commenced officially after the signing of the Bologna Declaration in 1999. The Bologna Declaration sets the main goals of the process, which is built upon the idea of creating a comparable, competitive and transparent European Higher Education Area in Europe. Among the major goals of the Bologna Process, one is to set up and extend a network of quality assurance in higher education, and to contribute to the improvement of higher education in Europe.

The guidelines and standards set by European Association for Quality Assurance in Higher Education (ENQA) firstly in 2005 as "ESG: European Standards and Guidelines for Quality Assurance in the European Higher Education Area", play a guiding role in quality assurance systems in higher education. The ESG framework requires higher education institutions (HEIs) in the European Higher Education Area (EHEA) to offer consistent and comparable services (http-1). In this respect, the following guidelines are adopted in setting up internal and external quality assurance systems:

- to raise students' and academic staff's awareness of quality assurance in higher education,

- to improve the quality of programs and to ensure sustainability of quality assurance in higher education institutions,

- to refer to the expertise of foreign specialists in quality assurance, and to conform to principles of transparency,

- to determine external quality assurance needs, and to give responsibilities to institutions that assume a role in external quality assurance.

Accordingly, each member country was asked to specify quality assurance standards in consideration of its education system, and evaluate the education system in the light of these standards. The member countries also establish the mechanisms to register quality assurance agencies for the review of quality improvement activities in higher education institutions. In this way, external reviewers assist higher education institutions in determining their level of quality (http-2). 
Turkey participated in the Bologna Process in 2001 as a result of the need for restructuring the higher education system and alignment with the European Union legislation. In Turkey, the Council of Higher Education (CoHE) is the main institution responsible for the implementation and monitoring of the Bologna Process requirements. CoHE has seen this process as an effective instrument for the restructuring of the higher education system. To this end, the following steps were taken in a chronological order:

- The Higher Education Council issued the "Regulation on Academic Assessment and Quality Improvement" in 2005. This regulation specifies the principles regarding the review of education and research activities in higher education institutions, quality improvement, approval and recognition of the level of quality by an independent external quality review.

- The Commission of Academic Assessment and Quality Improvement drafted the "Guidelines for Academic Assessment and Quality Improvement in Higher Education Institutions". These guidelines define processes and performance indicators required for the systematic functioning of academic assessment and quality improvement practices. The processes defined in guidelines are "strategic planning, institutional review, periodicity in quality improvement and monitoring in higher education institutions".

- In accordance with the Regulation on Academic Assessment and Quality Improvement, higher education institutions have set up Boards of Academic Assessment and Quality Improvement to manage quality assurance at the institutional level. The main duties of these boards are: (1) to review academic and administrative services in the institution according to the institution's strategic plan and goals, (2) to exert efforts to improve quality and have the level of quality approved, and to perform "internal review" in the institution, and to draw up an internal review report or have it drawn up, (3) if the institution undergoes an "external review", to make preparations for the external review, and to provide support to institutions, agencies or boards that perform the external review (http-3).

Many Turkish universities applied for Diploma Supplement (DS) label to enhance national and international recognition, and to ensure that Bologna requirements are satisfied in the higher education system. Furthermore, Turkish higher education institutions have also applied for the European Credit Transfer System (ECTS) label by preparing program and learning outcomes for all programs in the institution. CoHE has recently taken new steps at the national level regarding quality assurance in the Turkish higher education system, and established the Higher Education Quality Council of Turkey (THEQC) in accordance with the "Higher Education Quality Assurance Regulation" published in the Official Gazette in 2015. The working principles of the Higher Education Quality Council are based on:

- internal and external quality assurance of education and research activities as well as administrative procedures in higher education institutions,

- accreditation processes, and authorization of independent external review agencies,

- duties, authorities and responsibilities related to quality assurance (http-4).

In this connection, external evaluation and accreditation agencies that operate in the field of higher education in Turkey must receive a certificate of authorization from the Higher Education Quality Council in accordance with the "Directive on the Authorization of External Evaluation and Accreditation Agencies Operating in the Field of Higher Education". The accreditation agencies that receive a certificate from the Council are officially authorized to carry out accreditation procedures at the national level. The THEQC is a public legal entity with administrative and financial autonomy and special budget founded for fulfilling the primary duties of (1) performing external evaluation of higher education institutions, (2) coordinating the authorization and recognition processes of accreditation agencies, and (3) ensuring the internalization and dissemination of quality assurance culture in higher education institutions. As of May 2020, there are sixteen (16) evaluation and accreditation agencies, namely MUDEK, TEPDAD, FEDEK, VEDEK, EPDAD, HEPDAK, ILAD-ILEDAK, SABAK, TUADER-TURAK, ECZAKDER, TPD, IAA, SPORAK, DEPAD, AUDAK and PEMDER that accredit four-year bachelor degree programs in engineering, medical sciences, humanities, veterinary medicine, education, nursing, communication sciences, health sciences, tourism, pharmacy, psychology, theology, sports education, dentistry, open and distance education and landscape architecture programs (http-5). The THEQC is a full member of ENQA which is an umbrella organization that represents QA organizations of countries in the EHEA (http-6). Due to the Covid-19 
pandemic the transition to distance education in all national higher education institutions in Turkey, has made QA in distance learning a priority for the THEQC and the Council has declared the requirements for quality distance education as a working paper prepared by the Distance Education Working Group (http-7).

\section{CHALLENGE IN ACCREDITATION OF OPEN AND DISTANCE EDUCATION PROGRAMS}

Quality assurance necessitates the recognition of common standards however these standards and evaluation criteria are expected to manage the diversity and plurality of higher education in different disciplines and teaching methods. Distance education methods that provide flexibility and learner autonomy have always been questioned and discussed on the basis of quality when compared with the conventional/traditional face-to-face education. As the generally accepted quality framework is based on learning outcomes; many national and regional authorities use similar means to evaluate institutions and programs, both traditional and distance. However, the different means and media used in distance education need to be considered in reaching the specified outcomes. Another characteristic is the high number of students in mass education provided via distance education especially in Asian countries. These numbers may necessitate to find creative/innovative solutions and means to evaluate the institutional performances besides program learning outcomes (Belawati \& Zuhairi, 2007).

Concerning the challenges of QA implementation in open universities, scholars from Commonwealth of Learning (COL) have stated their concern that OUs appeal more to "underserved" populations but are expected to meet the same quality criteria as traditional universities though the concept of quality changes. An important indicator of quality has become the suitability of graduates for the labour market; however, authors drive our attention to factors like the geographic distance from the learner, openness (which means less rigid admission requirements), plurality of actors in both development and delivery, additional administrative tasks in the ODL systems, greater use of the ICT, distinct academic workload models: roles and responsibilities, recruitment of temporary/part-time staff which need to be considered while applying conventional QA frameworks to OUs. A neo-institutional approach is recommended to understand "change" in HEIs that concentrates on "structures, norms, rules and cultures" and their effects on the perception of change (Kanwar et al., 2019, pp.80-81). Another interesting point is that authors openly discuss that QA measures may be for compliance or improvement or both. Institiutions may have limited control over the external factors, but they can determine their reaction based on internal factors, such as regulations, norms and quality culture unique to the institution, through developing the appropriate QA policies, making plans and rewarding the continued involvement of staff in QA processes (Kanwar et al., 2019, p.93).

It is argued that distance learning challenges the core academic values of higher education (HE) such as "institutional autonomy, collegiality and shared governance, the intellectual and academic authority of the faculty, formal general education and degrees, site-based education and a community of learning" (Eaton, 2000). The threats versus these listed core values are discussed to emanate for example from internationalization and consortial arrangements (transnational education), dispersion of the faculty and the students, standardized courses and pervasiveness of non-degree training. The bias against distance learning grows in case these values are identified with the quality of the institutions. Contrarily, distance education enriches HE, the regional distance learning guidelines in the US e.g. highlight the similarities between site-based and electronically-based education. However, they also reflect differences in their approaches to teaching and learning, and the challenge to core values requires a rethinking on them. A strategy to meet this challenge and adapt to the unstoppable change is to see the contribution of ODL to HE values in fulfilling their purposes in an enriched manner through ODL. After such mentality change, the standards to address outcomes and competencies can follow so that more attention can be paid to what students learn (Eaton, 2000, pp.1-3). Harvey and Williams (2010) in their review of the fifteen years of "Quality in Higher Education" journal, emphasize that there's indifference among academia towards the consumerist approach pushed mainly by governments and senior managements. The critiques of QA processes due to bureaucracy and administrative burden can be replaced by more enthusiasm towards quality work, only through incentives, motivation for innovation, creativity and trust building among stakeholders. A major reason for indifference towards QA is the commitment to autonomy and academic freedom in HE which are very important. There is need for a better alignment of the external evaluation processes to daily academic 
activities and their internalization by staff both in research and teaching. The authors in the review they make, have generally provided more optimistic expectations for the internal evaluation processes, maybe also because QA is accepted in the ESG as a major responsibility of the HEIs which is a more independent area institutions can act.

\section{The European Response to the Challenge}

QA in HE covers all procedures and mechanisms in order to ensure quality at "micro, meso and macro levels" by sustaining the quality of programs, institutions and also national education systems (Vlachopoulos, 2016, p.187). The shared understanding for quality assurance as recognized by ESG 2015, has the common purpose of ensuring a high quality and relevant education based on learning outcomes and recognized by stakeholders involving the governments and employers. The need for a common language and guidelines among QA agencies towards developing a quality culture for e-learning was emphasized during an ENQA workshop in 2010 by the President of the organization. The QA agencies were recommended to use and interpret ESG as the backbone document however they were called to create additional materials to support them in monitoring both the progress and development of e-learning (ENQA Workshop Report, Grifoll et al., 2010, p.6).

A study printed by European University Association (EUA) in 2014 (Mapping Survey Oct-Dec 2013) reports that 91 percent of HEIs have already integrated e-learning into their teaching; in different modes of blended learning or online learning. It is reported that contrary to expectations, technical or open universities are not always leading institutions in ICT-supported teaching or digitalisation. There aren't many clear e-learning patterns and national policies, and strategies for e-learning are about to be developed. It is emphasized that even in the same country e-learning is implemented in different ways by different institutions. Some reasons cited are "institution profile and mission, availability of resources and funding, type of students and subject areas, different stages of experience in e-learning, levels of technology adoption and openness of staff'. The need for integrating a QA framework for e-learning at national and organizational levels is highlighted as a result of this survey conducted (Gaebel et al., 2014, pp.7-9). However, despite the trend in the EHEA, QA in e-learning has not been a popular area of interest and only 23 percent of the national QA agencies have reported about their special consideration of e-learning (ENQA Occasitional Papers 26, Huertas et al., 2018, p.1).

A comparative analysis of the ESG 2005 and ESG 2015 indicates that the four basic principles remaining the same, the recognition of diversity and the importance of supporting a quality culture have found more emphasis in the latter. The developments and trends conducive to the revision of the ESG have been the shift to student-centered learning, need for flexibility in learning, recognition of competencies gained through informal education, internationalisation of HE, digital learning and new modes of delivery. As a modification of ESG 2005, the text of 2015 refers to the learning environment and its ties with research and innovation. However, the scope of ESG in the text of ESG 2015 is again emphasized to be applicable to all HE provision offered in the EHEA, "regardless of the mode of study or place of delivery". Thus they shall apply to cross-border, transnational HE, formal and informal learning and all different modes of provision such as e-learning (EQUIP Project Paper, pp.1-2). Reflecting this mentality that ESG also laid the foundation for different modes of learning including web-based provision and its regulations, there were minor revisions to ESG 2015. These standards are also applicable to e-learning, but innovative QA methods are needed to be developed with new indicators (Huertas et al., 2018, p.21). This means that both HEIs and QA agencies shall adapt their QA systems according to the particularities of e-learning. It is to be kept in mind that the technology enhanced learning is accepted as an integral part of QA system for the EHEA.

The European perspective on the QA of distance learning is closely related with the internationalization of HE. Distance education makes an important percent of transnational education across national borders. Good partnerships are concentrated on both staff and curriculum development so that participants can enjoy the opportunity of sharing different experiences and seeing different approaches to teaching and learning. This enriches them in their individual career and institutional development (Campbell \& Van der Wende, 2000, p.11). However transnational education makes QA more complex, e.g. joint degree programs. The challenge is for QA agencies in their quest to adapt their processes to new modes of delivery and redefine 
quality accordingly in terms of curriculum design, security of assessment, training academic staff for both international collaboration and new media for teaching. The digitalization of $\mathrm{HE}$ and the blended learning environment of dual-mode universities involves new actors into QA processes, such as telecommunications companies, publishers, software and IT companies, corporate and virtual universities. The agencies then need to consider their participation as well to the processes. The paradigm of lifelong learning and the increasing competition in recruitment increase the interest for technology enhanced learning, thus new capabilities of ICTs (Campbell \& Van der Wende, 2000, pp.16-17). The changing circumstances are not limited with competitiveness and interest in technology. Among the effects of globalization such as the unforeseen Covid-19 virus pandemic has resulted in a very fast transition to all forms of distance learning.

\section{Any Consensus among Different Models?}

A major consensus is on the importance of a dynamic and flexible systems approach for the progress of distance education to meet different learner needs. The one-size-fits-all course structure prevents the system of $\mathrm{HE}$ from responding to the changing needs of learners and necessities of a competitive environment. If HEIs are to be responsive, all stakeholders need to be aware of the pros and cons of new media and what they imply in terms of reaching learning outcomes via distance education. This dynamic systems approach is conducive to taking each institution's vision, mission and organizational structure into consideration (Saba, 2012). The literature on QA in ODL focuses on a holistic and systematic approach, as such QA is perceived as a continuous improvement through which the staff gets familiar with quality issues, and strong formal quality policies are made. In the meantime, the institutions get ready to develop a sustainable quality philosophy which under strong leadership can motivate both staff and students for improvement (Vlachopoulos, 2016, pp.189-190). Reviewing different methodologies for quality assurance in e-learning, it can be seen that the focus on content, pedagogy and learning results has shifted to a systemic evaluation of processes; educational experience and learning. Despite the apparent need for a holistic approach to consider all quality factors as "inputs, resources, processes, outputs and outcomes" even accreditation agencies may show the tendency to focus more on some specific dimensions and stakeholders, e.g. preferring more measurable inputs rather than outputs (such as the employability of graduates). These common factors of QA in HE, need to be elaborated with indicators specific to online education at micro (individual learner), meso (course) and macro (program) levels, and tailor made for each institution's context with the involvement of all stakeholders (Esfijani, 2018, pp.65-70).

Do institutions re-invent the wheel while trying to formulate their own way to quality? A matrix of different quality standards published in the US were listed as: executive commitment, technology infrastructure, student services, design and development, instruction and instructor services, program delivery, financial health, legal and regulatory requirements and program evaluation (Frydenberg, 2002, p.10). Through various benchmarking models (E-xcellence+, eLearning Benchmarking Exercise, First Dual-Mode Distance Learning Benchmarking Club), there's a high level of correspondence where similar factors are explained with differences in terminology and interpretations. Universities are in a structural and innovative transition towards technology enhanced learning which brings a paradigm change for learning and teaching. The common point of different forms of technology enhanced learning is the use of knowledge and technology to "connect" people with each other and with learning resources for the purposes of formal, nonformal and informal learning. E-learning requires a change from traditional organizational and pedagogical perspectives. For quality e-learning, different aspects of "accessibility, flexibility, interactiveness, personalization and productivity" need to be embedded in the "products, management and services" pillars of e-Learning (Ossiannilsson and Landgren, 2012, pp.49-50).

A process-oriented and dynamic life-cycle model for QA in e-learning suggests to promote a culture of continuing self-improvement through three stages: (1) planning and analysis; (2) design, prototype and production, (3) post-production and delivery. It is emphasized that a purposeful and informed design of the learning tasks and provision of scaffolding resources is the key to quality e-learning which is mainly focused on improving the student's learning experience (Abdous, 2009, p.282). Another four-phase evaluation model (PDPP evaluation model) developed by Chinese scholars for e-learning courses is composed of "planning, development, process and product evaluation" phases. Planning involves analysis of market demand, 
feasibility study, target student group and needs analysis, determination of course objectives and financial evaluation. The development phase consists of instructional design, course and website design, production of content based on flexibility, interaction, support and assessment. Processes to be evaluated are technical support, web utilization, learning interaction and learning support with an eye to flexibility. In the final phase, product evaluation means measurement of student satisfaction, teaching and learning effectiveness and sustainability of the services (Zhang and Cheng, 2012, p. 66).

The evaluation of student learning is critical in the accreditation of distance learning, in order to assure that the students achieve the learning outcomes. Technology provides the necessary learning platforms with multiple tools and assessment methods (Krause et al., 2015). This is also applicable to competency-based education where a student's understanding of a topic is evaluated through demonstration of mastery in certain skills or learning outcomes related to a specific topic, and the students can master their subject skills at their own pace. This is achievable via ODL media and the suggested methods for evaluation of student performance are written papers, portfolios and projects. Institutions can develop their own assessment criteria according to their student profiles and for each case specific to the type of program and discipline. For an efficient self-paced competency based education, for example, the demonstration of competency is more critical than assessment of learning; thus, summative assessment of the demonstrations, practices can be weighed more. In this case, engagement one-to-one with a faculty member/mentor maybe more supportive than peer interaction. It is important that the necessary tools are provided to learners in order to ensure that the learning outcomes are met. So, there is need for specific criteria up to the nature of the course/program according to targeted qualifications and program outcomes (Krause et al., 2015).

The accrediting agencies generally use the existing standards for site-based courses to evaluate online learning environments. There are different modes of delivery and different approaches to QA by HEIs where agencies try to find out the most appropriate way to support them on their path to quality HE. The distinctive features of distance learning and the expectations from different role-players in different quality pillars of ODL (institutional commitment, curriculum and instruction, faculty support, student support, evaluation and assessment) need to be considered in modifying the accreditation guidelines. This is because stakeholders may have different perceptions and definitions of quality as a result of their negotiations around different power relations and interests during the planning process. In a classical systems model, where the sociopolitical aspects of curriculum planning and unequal power relations among the planners are ignored, it is difficult to evaluate if the planners have made the right decisions and whether different expectations of the stakeholders are taken into consideration or not (Benson, 2003, pp.145-147). Some quality frameworks emphasize program planning and curriculum development more than others and argue that the processes must be ethical as well, besides being technical and social. The different dimensions of quality, at different levels can be classified as (1) quality for improving the reputation of the institution, (2) quality through accreditation where the core program meets accepted set of learning outcomes, (3) quality as efficient and effective (collaborative) course development and (4) quality as effective pedagogy through student engagement with the course content (Benson, 2003, pp.150-151). The difficulty to adapt the traditional accrediting paradigm to new educational environments may lead to a paradigm change which is certifying the individual (learner/instructor) instead of accreditation of the institution. E-learning has changed the traditional indicators of quality such as contact hours and physical attendance, and turned them into indicators like interaction and qualification of the instructor (Pond, 2002, pp.3-5). The problem is that "educational delivery evolves faster than QA methods" whereby it has to be determined according to student's level of learning and his/her learning experience which means that the institution shall be evaluated in the context of students' experiences and feedback from all stakeholders (Pond, 2002, p.6).

Concerning the quality of distance education systems, it can be argued that the distant mode improves the quality of education provision, firstly because the remotely located/distant learners can easily access the learning environment (ENQA Workshop Report, Rubin, 2010, p.19). Unless there is a digital gap and the technology enhanced learning is not a further disadvantage to some learners, it is an indicator of quality indeed. E-learning efficiently can bridge the distance gap; however, the learning content must be updated regularly in order to improve professional competences, and the teaching methodology must be designed to help the learner master the learning material. Also, owing to the huge competition among the content developers in the ODL field (unlike the situation with instructors in the conventional education), there is 
need for standards such as ISO 19796-1 for e-learning standardisation. Since there is no comprehensive e-learning quality evaluation system to monitor all functional aspects of distance teaching, it is critical that independent accreditation agencies monitor all processes, however, in a professional, transparent manner based on "trust" between stakeholders (ENQA Workshop Report, Rubin, 2010, pp.23-26).

HEIs in checking the suitability of different QA models, may choose generic or specific approaches. Adaptation of generic approaches like ISO 9000 or EFQM is a great deal of effort, on the other hand, approaches specific to learning may not have wide acceptance. Though many institutions are aware of the need for QA mechanisms they may not have the instruments to fulfill the requirements of different agencies and adopt their approaches. ISO 19796-1 is recommended as a reference framework and instrument for adaptation and adoption of different quality approaches for organization-specific development of quality system in e-learning. An example discussed is that the management guideline principles of Total Quality Management can be combined with content guidelines specific to e-learning, so the framework is functional as a roadmap and used as a collection/pool of criteria. With this perspective, the steps to a quality system in an educational organization are; context setting, model adaptation, model implementation/adoption and quality development, where the participation of many actors and their consensus is required for each step (Pawlowski, 2005, pp.4-7)

The agencies are important for monitoring if e-learning meets stakeholders' needs or not. Since ESG 2015 does not emphasize specific statements on e-learning, agencies must adapt to alternative teaching and learning with the understanding that e-learning is an integral part of $\mathrm{HE}$ and should not be evaluated separately. Among priorities in this adaptation, ENQA's report lists firstly development of teachers' e-maturity and supporting ICT skills of learners. The professional competence and appropriate educational strategies to manage distance education (DE) are important, as well, through mechanisms such as reward systems for dedicated teachers or the use of social media for collaborative learning (ENQA Workshop Report, Ossiannilsson, 2010, pp.44-45). This is a heavy burden since distance learning requires expertise in all its components and its challenges necessitate innovative approaches.

\section{The Cultural Diversity}

Innovative way of thinking about e-learning asserts that it isn't just a delivery mode besides other educational media, but is a new approach to teaching and learning. This is why followers of this idea see a necessity for "e-quality", norms of which are also embedded in cultural-pedagogical issues and contexts. Since different e-quality models emanate from benchmarks, there is need for a theoretical approach which can explain socio-cultural aspects of quality criteria from a systematic point of view. The benchmarks all come with their own philosophy and certain cultural, pedagogical norms and values which is dominantly Western pedagogy. Seeing education as a social and cultural enterprise, for a working quality framework, cultural diversity must be recognised at both micro and macro levels. This means that quality criteria need to be adaptable to different cultural and institutional contexts especially for developing countries (Masoumi and Lindstrom, 2012, pp.28-35).

The QA models need to be selected also with an eye to the translation and adaptation of the international standards that may reflect different pedagogical culture and traditions inapplicable as they are in some national systems. In a study by Gao and Legan (2010), about the adaptation of QM rubric to review courses in China, the authors emphasize that the items in the rubric had to be adapted according to local habits of mind and cultural setting. The QA agencies and stakeholders must be aware that they appeal to international thus multicultural audiences with their standards and different design suggestions. The role(s) of the teacher and learner; different learning styles, regulatory policies such as learner privacy, material/ textbook adoption, accessibility may be among issues that are worth more attention compared to others, due to different cultural settings and institutional structures (Gao and Legan, 2015, p.210). In addition to the cultural diversity that may take place at individual, societal and institutional levels; the components of the ODL system need to be taken into consideration when speaking about accreditation of distance education institutions and programs; such as learning materials, instructional design, assessment, support services for students and teaching staff alike. In this connection, institutions need human resources specialized in ODL when establishing their own systems for QA and accreditation (Kocdar, 2011). The review teams must be 
composed of these specialists besides field/discipline experts so that they can understand and evaluate issues, necessities, technologies, organizational structure and staff qualifications required by open and distance education. "A true e-learning expert is someone who is really aware of the novel opportunity of having access to the record of learning interaction and engagement", thus this is also a quality culture where e.g. the composition of the panels gets very important (ENQA Workshop Report, Mulder, 2010, p.31).

In a study by Manatos and Huisman conducted to see how national accreditation agencies interpret ESG and adjust them to their domestic context, it was seen that national QA frameworks often deviate from the ESG. In fact ESG provides a source of assistance for both HEIs and agencies of external QA and functions as a common frame of reference. So it is a generic guidance as the authors emphasize. National agencies translate ESG in a metaphorical sense to their own context and edit them. The researchers give reference to the Scandinavian institutional theory and explain that policies and practices during their travel to another country or from one policy area to another, are subject to interpretation, editing, adaptation and translation. This interpretation and its magnitude is up to the feature of the idea, its specific content and the relationship between the recipient and source. It is seen that both ESG and the national frameworks are used in the reports of accreditation agencies. However, there is also no radical alteration of the standards since this could put the legitimacy of the agency at stake as a member of ENQA or the European QA Register for HE (EQAR) the organization where agencies are registered at European level. It is explained that technical elements are copied more, and less tangible issues like the quality culture change in reports, another result is that the public HEIs apply ESG more than private institutions (Manatos and Huisman, 2020, pp.4950). The Bologna regime of HE sees accreditation as a way to sustain the quality of programs, credits and degrees. However, a European Accreditation Agency is not welcome, because the recognition of credits and degrees is defined within the autonomy of the HEIs (Campbell \& Van der Wende, 2000, p.23). This is why, guaranteeing the minimum quality through national QA systems and guides may be more preferred as in the case of Turkey.

\section{AUDAK: PIONEER ACCREDITATION AGENCY IN TURKEY FOR ODL PROGRAMS}

AUDAK was founded on $31^{\text {st }}$ July, 2017 as an association to function as an external QA agency to inform public and private institutions about management and organization of ODL, evaluate and accredit ODL degree and non-degree programs. As previously stated, AUDAK had to be approved and registered by The Higher Education Quality Council of Turkey (THEQC) in order to be able to accredit open and distance education undergraduate programs in Turkey. Within the Turkish higher education system, THEQC is responsible for;

- internal and external quality assurance,

- evaluation of education, research and social contribution activities and administrative services of higher education institutions based on the national and international quality standards,

- authorization, recognition and monitoring of independent external evaluation and accreditation bodies (http-8).

With the vision of THEQC to be an effective and internationally recognized organization in the field of quality assurance in higher education, its application for full membership to The European Association for Quality Assurance in Higher Education (ENQA) was accepted by ENQA for a 5-year term as of 28 April 2020 (http-9).

The evaluation criteria of THEQC are based on internationally accepted practices such as ESG in particular. Accordingly, the criteria for the authorization of the National External Evaluation and Accreditation Bodies are grouped under seven (7) main headings, which are listed below (http-10):

1. The organization applying for registration must have pre-defined and declared mission and objectives. Thus, it should continue its activities in line with these objectives and broad stakeholder participation should be ensured in its governance processes and practices. In addition, applications and criteria for output-oriented program accreditation must be proven to be reliable and compliant with the national and international standards (especially ESG part III). 
2. The institutional and financial structure of the organization applying for registration must be sound and sustainable, in accordance with the legislation and the field of activity.

3. The organization applying for registration should act independently in terms of its organizational structure, operational processes and responsibility for official results.

4. The organization applying for registration must regularly publish general evaluation reports (Thematic Analysis Report) that analyze the results of program accreditation activities.

5. The organization applying for registration must have adequate and appropriate resources both in terms of human resources and physical infrastructure to be able to carry out the program accreditation activities.

6. The organization applying for registration must have the necessary internal quality assurance processes in place to monitor, evaluate, and secure the output of its activities and to perform continuous improvement activities.

7. The applicant institution must be involved in external evaluation processes to assess the compliance of its activities with national and international standards (especially ESG part III) and to continuously improve the quality assurance system.

AUDAK made its formal application to The Higher Education Quality Council on 12.March.2020 to obtain a Certificate of Quality Assessment Registration. On April 10, 2020, it obtained the National Registration Certificate, valid for two years as an accreditation agency (http-11)

The steps taken by AUDAK for the registration process are summarized below:

1. Pre-registration: THEQC pre-registration e-form was filled for AUDAK.

2. Application file: The AUDAK Self-Assessment Report was prepared with evidence that the seven (7) criteria mentioned above had been met.

3. Application: AUDAK electronic application was made via the System of Accreditation Organizations (AKSIS).

4. Preliminary assessment: AUDAK's self-assessment was evaluated by the THEQC experts.

5. Application evaluation report: The report prepared within 30 days by the assigned commission was submitted to the THEQC.

6. Decision: THEQC granted AUDAK 2 years of authorization.

7. Appeal: AUDAK has the right to appeal to the THEQC within 30 days (http-12)

As the result of the above summarized legal procedure, AUDAK is an agency authorized by the THEQC to accredit distance bachelor degree programs in business administration field. What is unique about AUDAK among other national agencies is its specialization on ODL and its evaluation criteria that focus on means to meet the learning outcomes as stated in the Turkish Qualifications Framework for Higher Education. Besides, its main characteristic is its inter-disciplinary nature separating it from the other fifteen national accreditation agencies authorized by the THEQC, since AUDAK aims to appeal to different disciplines provided via open and distance education. This first application to the THEQC has been made for Business Administration since there is no national QA agency accrediting business schools in Turkey. CoHE has decided for the ESG as the roadmap to quality in HE including internal and external QA processes. In this connection, the association aims to guide ODL providers to meet European and other internationally recognized standards, and assure sustainability of their quality systems. THEQC seeks whether the national agencies consider standards of international agencies in the related discipline(s) or not.

For example concerning management education worldwide, many business schools seek accreditation by EFMD (European Foundation for Management Development) EQUIS (European Quality Improvement System), AACSB (Association to Advance Collegiate Schools of Business) or AMBA (Association of MBAs). Among them European EQUIS with CEL (Certification of e-Learning) based on benchmarking and AACSB International have covered QA in online education. According to AACSB Distance Education Task Force Report (1999) about quality issues in distance learning, among business schools accredited by AACSB International, those institutions that offered distance programs (53 percent of respondents) did so because they preferred to build their system and pedagogy on flexibility, collaboration, hybrid/blended 
approach, team building; and competency in technology support and targeted to have students from different geographies both within and outside the US. Schools that did not offer distance programs (47 percent of respondents) expressed the idea that degree via $\mathrm{DE}$ would weaken the quality and brand of their business school (Popovich and Neel, 2005, p.238).

EFMD has declared its intention to fill the void for a comprehensive e-learning quality system in operation. An important criterion is the suitability of the faculty for teaching online, some members of the faculty may not be ready even after a training. This is why some virtual universities have preferred to recruit adjunct faculty. The case of U21Global consortium and its four-step policy of recruitment may be given as an example of this understanding: recruitment; training and accreditation; supervision and mentoring; reflection and performance appraisal (Sixl-Daniell et.al, 2006, pp.2-3). AUDAK aims to be an actor in the evaluation of international programs as well, where there is an increasing need due to internationalization of curricula and student profiles. As regards transnational education, some international projects and consortiums are shown as failures in online education, and this critique may be due to their international context which makes QA processes in distance learning even more complex to implement. However, e-learning may be done well in some departments and poorly in others, even within the same university. The lenses that do not see e-learning as evolved from conventional teaching and learning, but approaching it as a "discrete" mode of delivery and examining the "factors specific to it" can be a more promising solution for quality education (Oliver, 2005, pp.173-175). This is why it has been the motto of AUDAK in determining its criteria for quality distance education. Besides, despite the competition and turbulence in the international arena, "national quality systems" may be more comprehensive and appealing that can clearly and consistently guide institutions on their path to continuous improvement. THEQC after Covid-19 pandemic has announced a framework for distance education and quality assurance system and listed the main elements of quality distance learning as: distance education policy, infrastructure and accessibility, competencies, learning and teaching processes, professional human resources and support services, information security and ethical aspects (http-13).

\section{AUDAK's Evaluation Criteria}

AUDAK evaluation criteria for Open and Distance Education Undergraduate Programs aim to ensure the quality assurance for open and distance education undergraduate programs consisting of at least 8 semesters or equivalent (240 ECTS credits), and support the continuous improvement of these programs. The institution applying for the evaluation of an open and distance education program at the undergraduate level is obliged to prove that the program in question meets the criteria. The general criteria are grouped under 10 headings, which are stated below:

Criterion 1. Students: These are the criteria regarding all student services offered during the period from enrollment to graduation.

Criterion 2. Program educational objectives: These are the criteria indicating the qualifications needed by the program to meet its instructional objectives.

Criterion 3. Program outcomes: These are the criteria that help program outcomes align with the program educational objectives. AUDAK degree programs are determined based on the program outcomes evaluation criteria stated by the Turkish Higher Education Qualifications Framework and the undergraduate education qualifications in the Standards and Guidelines for Quality Assurance in the European Higher Education Area (ESG, 2015).

Criterion 4. Continuous improvement: These are the improvement and development-based criteria to ensure the sustainability of the program.

Criterion 5. Curriculum: These are the criteria for each program that require a curriculum that supports program objectives and outcomes.

Criterion 6. Faculty qualifications: These are the criteria to ensure the adequate number and quality of the teaching staff and ODL experts to meet the needs of the program in the field of open and distance learning.

Criterion 7. Infrastructure/facilities, equipment, procurement and archiving: These are the criteria for the competencies related to infrastructure/facilities, equipment, procurement, and archiving to provide the instructional services of the institution and ensure interaction between its stakeholders. 
Criterion 8. Institutional support and financial resources: These are the criteria regarding the financial power of the institution to ensure the quality and sustainability of open and distance education programs.

Criterion 9. Administrative structure: These are the criteria related to management activity that demonstrates the sustainability and competitive superiority of the organization.

Criterion 10. Program-specific criteria: These are the criteria related to the instructional plan determined according to the qualifications defined in the specific field of each program (http-14).

The European counterparts; national agencies in Norway (NOKUT), Sweden (NAHE) and the UK (QAA) have guidelines for quality assessment of distance learning. Such guidelines are as expected, based on the differences between a distance teaching university and a conventional one. The context/environment of the university and its characteristics; the inputs such as the student profile, teaching staff (resident and collaborating), technology infrastructure; teaching process homogeneity and products including academic, personal and professional outcomes are to be evaluated. The assessment process can be divided as institutional and degree (program) levels; however, the dimensions of both levels must be elaborated with specific indicators, standards and evidences for each dimension. The institutional level covers aspects common to all distance programs of the institution such as the mission, vision, delivery system, infrastructure, QA policy and internal QA mechanisms and information systems. Evaluation at the program level specifies how the mentioned aspects, policies and mechanisms work for each study program with reference to its instructional design, learning assessment and learning outcomes (ENQA Workshop Report, Huertas et.al, 2010, pp.1216). The most critical point is that the references must be based on indicators, standards and their evidences specified for distance learning and online education. This has been the understanding when determining the indicators for general and program specific criteria by AUDAK.

As in the case of accreditation of conventional programs, during accreditation processes of distance teaching institutions, self-evaluation reports are prepared and an external panel reviews the subject report prior to their site visit which is recommended to be supported by online interviews so that all stakeholders can be heard during the assessment. When it comes to distance education, it is important that the external review panel is well-informed about the specific nature of the institution and most preferably are trained in an e-learning system. Besides the evaluation of the virtual campus/VLE (Virtual Learning Environment), the online interviews with the students are critical as well. The strategic plan, the budgetary information of the institution constitute other important pillars of evaluation in coming up with a decision about the subject institution(s) (ENQA Workshop Report, Huertas et.al, 2010, p.16). In the case of distance teaching institutions generic evaluation is the backbone for specific evaluation of the program(s). Since there is a limited number of case-studies available in the literature and limited number of reports by the QA agencies for the evaluation of distance teaching HEIs, evaluators need to be more alert about the implementation and differences of distance learning.

ENQA's Occasional Paper published in 2018 has recommended QA agencies that they make a proper and appropriate interpretation of the ESG for all modes of teaching and learning including e-learning. Teaching and learning process, learning resources, the VLE, student support system and the pedagogical innovations it may require according to the institution's circumstances are emphasized in the paper by subject experts. Among the indicators, the involvement of all stakeholders in developing the e-learning criteria (for institutional or program evaluation) and the availability of the criteria to public are especially highlighted. The agencies are required to have very effective public relations and transparency so that they can build trust among all stakeholders which is very important so that they can be accepted as partners and guides on the continuous path to quality. For the implementation of the evaluation by an agency, its is reminded that with the self-assessment report, all necessary data to access the learning environment (system/ VLE, classrooms, debate forums, materials) should be provided to the panel prior to the site visit. The institution's pedagogical model (instructional design), innovation and technical infrastructure, experience and knowledge of staff, services and support for both students and faculty should be examined. The diversity of staff for e-learning (authors, lecturers, tutors, mentors, study directors, coordinators, technical staff etc) must be considered during the planning of interviews with different stakeholders. The peer-review experts/ panel (including student reviewers) must have experience with online teaching and/or learning, and they must be trained about e-learning (Huertas et al., 2018, pp.17-19). The guiding role of the agencies is very 
clear in their expected civic engagement, independent and autonomous structure composed of field experts and having inter-disciplinary character so that they can disseminate the know-how in distance education.

Integration of e-learning in the ENQA guidelines for QA has been suggested through an international network of organizations such as EADTU, EDEN, EFQUEL, ICDE, and benefits of participating to benchmarking exercises has been recommended. Among these benefits; participation of the staff to internal processes of the institution, transparency of the educational processes and reflection on issues such as policies, documents and web pages can be given (ENQA Workshop Report, Ossiannilsson, 2010, p.35). A self-assessment of the institution and increasing awareness on strengths and weaknesses of the institution are the minimum outcomes and benefits of the QA processes. The intersection set of different European models such as EADTU's E-xcellence+, ELQ-model of Swedish National Agency (NAHE) is the priority of a holistic approach when integrating e-learning criteria to QA processes of HEIs. NAHE has set its criteria as "material/content, structure and virtual environment, communication, cooperation and interaction, student assessment/flexibility and adaptability, support (student and staff), staff qualifications and experience, vision and institutional leadership, resource allocation, holistic and process aspect". These methods can be adapted for different delivery modes of e-learning besides mobile, distributed, blended or integrated learning (ENQA Workshop Report, Ossiannilsson, 2010, pp.41-42) EADTU's E-xcellence Quality Associates is based on benchmarking at strategic management, curriculum design, course design, course delivery, staff support and student support for seeking improvement with four core values of HE: accessibility, flexibility, interactiveness and personalisation (http-15). Their fulfillment is among objectives of AUDAK criteria, that can be grouped as "students, program/curriculum, management and faculty" whatever the distant mode of delivery is and the media used are for technology enhanced learning.

Among the mostly cited success factors for distance education; university leadership, infrastructure and faculty support systems can be given. The administrative policies and investments, technology facilities and applications, human resources management for continuous career development, training and incentives are among components of strategic management and infrastructure. As regards support systems, methods for the engagement of both faculty and students are important. The willingness and readiness of faculty to use new technologies and distance education techniques with appropriate pedagogy are among basic criteria for distance education systems (Angolia and Pagliari, 2016). All these pillars necessitate certain technical and pedagogical standards to be fulfilled so that the learning objectives can be met. On the student side, motivation and provision of skills, like time management and digital literacy are indicators for the quality of student experience in e-learning. It is the responsibility of the HEIs to define and update the required technology infrastructure for their students' individual participation. It is up to QA agencies to monitor the implementation/practice and show HEIs their shortcomings, areas for improvement and innovative ways of doing so. One of the key indicators of improvement is the adaptability of DE courses to different learning styles. The successful management of these processes also lies with the university's leadership, culture, administrative and financial resources so that the institution can "keep pace with the learners" and developments in ICT (Angolia and Pagliari, 2016). QA in distance learning is a huge task since all indicators are indispensable, integral parts of the system and what is more, the cases all need to be evaluated from a holistic but unique way for each institution/program. This has been the mentality in developing AUDAK's criteria and their indicators for evaluation of distance program $(s)$.

\section{AUDAK Criteria for QA in Open and Distance Education}

A summary of AUDAK's criteria for quality open and distance education bachelor degree programs are as follows (http-16):

\section{Students}

- Students must have achieved the program outcomes.

- Admission requirements must be monitored and evaluated on a year-by-year basis.

- Admission of students by horizontal and vertical transfer must be carried out according to the relevant legislation.

- Opportunities to encourage student mobility must be provided. 
- The necessary orientation must be provided for students to become "open and distant learners."

- Consultancy/e-consultancy services must be provided to support students.

- Academic counseling/e-academic counseling must be offered to guide students on career planning.

- Students must be offered e-support services.

- Students must be offered e-guides.

- Students must be offered online social networking opportunities.

- Learning and evaluation methods must be provided via electronic media.

- Students' achievements in all courses and other activities must be evaluated through consistent evaluation methods.

- Student Information System must be used in the institution.

- Relevant policies must be in place for the evaluation of student complaints.

\section{Program educational objectives}

- For each open and distance education program to be evaluated, the program instructional objectives must be defined and published on the website of the institution.

- These objectives must

- be in line with the AUDAK's definition for program educational objectives,

- comply with the mission of the institution and the unit,

- be determined and updated as needed by including internal and external stakeholders in the process, and

- an institutional alumni e-tracking system must be launched and used.

\section{Program outcomes}

- Program outcomes must be defined to be compatible with AUDAK program outcomes.

- Evidence that program outcomes have been achieved must be provided periodically.

- Students who have reached the graduation stage in open and distance education programs must be proven to have achieved the program outcomes.

\section{Continuous improvement}

- The results obtained from the assessment and evaluation systems must drive the improvement of the relevant program.

- To ensure the sustainability of the program, the necessary quality strategies for improvement must be implemented.

- Work processes in the relevant unit must be analyzed and work flow diagrams must be created.

\section{Curriculum}

- Each program should have a curriculum that supports program instructional objectives and outcomes.

- Teaching methods to be used in the implementation of curriculum should be provided to students through open and distance education.

- There must be an integrated institutional Management Information System to secure the curriculum and ensure its continued development.

- The curriculum must include basic sciences education relevant to the related discipline, vocational education and elective courses.

- The curriculum, learning environment and materials must be designed and presented in accordance with open and distance learning principles.

- Instructional media and materials must enable students to reach program outcomes.

- Open and distance learning systems must provide instructional models and online tool options appropriate to the needs of students and educators.

- Open and distance learning environments must be designed to allow access and cooperation to internal and external stakeholders through the social networks of the institution. 
- Teaching staff (faculty) and technical staff must be involved in the development of curriculum content, learning environment and materials.

- Open and distance learning environment and materials must have adequate level of interaction (student-content, student-student, student-teacher interactions).

- Open and distance learning environments and materials should provide feedback to students through self-assessment activities (exercise questions, trial exams, etc).

\section{Faculty qualifications}

- Faculty/teaching staff must be at an adequate academic level and have the number and quality to meet the needs of the program in the field of open and distance learning.

- Teaching staff must ensure that the program is maintained, evaluated and improved effectively.

Infrastructure/ facilities, equipment, procurement and archiving

- The institution must use open and distance learning technologies in provision of education and ensure interaction between its stakeholders.

- The institution offering open and distance education programs must have a Learning Management System (LMS) and Unit Management Information System and this system must be integrated with the Management Information System (MIS) of the parent institution.

- The unit(s) delivering the open and distance learning processes must have physical spaces (offices, offices, centers, studios, exam centers, etc.) and these spaces must be adequately equipped to achieve the educational objectives and program outcomes.

- The technical specifications for the physical spaces and the equipment that these spaces have must be based on stakeholder needs.

- Students must be allowed to do extracurricular activities to meet their social and cultural needs.

- The necessary infrastructure must be provided for the programs that have practice-based courses.

- The technical infrastructure must be adequate for the scientific research of students and faculty members.

- All systems utilized to communicate and provide information in open and distance learning programs must be reliable and have urgent action plans.

- All personal and academic information and documents related to students must be archived, stored and protected in a confidential and secure electronic environment.

- System maintenance and monitoring and performance evaluation must be carried out in accordance with the set standards and must be updated when necessary.

- Students must be provided with an institutional virtual library to reach information and improve their study skills.

- The necessary safety precautions must be taken in the offline and online learning environments that students use.

- All kinds of physical and online infrastructure arrangements must be made for the disabled.

\section{Institutional support and financial resources}

- The main institution's administrative support, constructive leadership, financial resources and strategies for their distribution must ensure the quality and sustainability of open and distance education programs.

- The financial resources of the institution should be sufficient to employ a qualified teaching, administrative and technical staff and to sustain its professional development.

- The institution must have the necessary financial resources for the infrastructure and improvement of each program. 


\section{Administrative structure}

- The institution/organization providing open and distance education services must have an Organization Manual.

- The work processes should be organized to support the achievement of program outcomes and educational objectives.

- The unit must have a quality assurance policy. The Quality Manual, in which the sub-policies reflecting this policy are defined, should be shared electronically with the internal and external stakeholders.

- The unit should have the methods to plan, implement, control and take measures in-unit mechanisms for the operation of the open and distance education system.

- While providing resources for open and distance education, the unit must take into account the hardware, software, human resources, teaching/research needs, and technological developments.

- The mission statement of the unit must state that it intends to provide qualified open and distance learning service, which must be published on the unit web page for all stakeholders.

- The unit vision must state how it envisions itself in the future in the field of open and distance learning, which must be published on the unit web page for all stakeholders.

- The unit must prepare a strategic plan in accordance with its mission and vision, and this plan must be published on its website.

- The unit must certify that it complies with ethical principles in promotional materials and activities for prospective students.

- The unit must comply with legal regulations and ethical principles for student admission.

- The unit must publish clear, accurate, objective, up-to-date, and easily accessible information about its programs and activities in print and electronic form.

- The unit must announce that it implements fair and transparent processes in recruiting qualified staff.

- The unit must perform its staff training based on continuing education principles.

- The service outsourced from outside the institution/organization must be secured by contracts.

- Research and innovations in the field of open and distance learning must be considered high-level activities and supported with career development incentives.

- The newly-hired personnel who are to work in open and distance learning must be provided the necessary orientation.

\section{Program-specific criteria}

Program-specific criteria refer to the additional criteria for the curriculum determined by taking into account the qualifications defined in the field of business administration.

AUDAK as an accreditation agency is a pioneer organization firstly because it is the first national accreditation agency focused on open and distance education. Secondly, AUDAK aims to provide counselling and evaluation/accreditation services to a wide spectrum of institutions, such as distance education/continuous education centers of HEIs, private companies that produce learning materials for ODL, public and private institutions that provide non-degree, informal, lifelong learning courses/programs, Short Learning Programs (SLPs), certificate programs, Massive Open Online Courses (MOOCs). These areas AUDAK is interested are in addition to its role as the program evaluation authority granted by THEQC. These areas put forth further responsibilities for the quality of "lifelong learning". Since blended learning/technology enhanced learning in $\mathrm{HE}$ is becoming a general practice, there is need for application of quality standards for open and distance education/e-learning with the collaboration of all HEIs/universities. 


\section{CONCLUSION}

Most of the universities already have policies for ICT-supported teaching or digitalization, and have integrated e-learning into their curricula through different modes. Many countries have developed their distance education strategies in line with international organizations and have their own national authorities and working groups devoted to studying the pros and cons of digitalization and are making collaboration to find ways of developing and sustaining quality in their systems, institutions and programs. The need for integrating a holistic and systematic QA framework for e-learning at micro, meso and macro levels has already been accepted and declared by the main QA organizations and agencies in the EHEA as well. Through the economic and technological effects of globalization or a pandemic which causes a global alert and trigger a very quick transition to technology enhanced learning, highlighting the importance of digital skills for everyone, open and distance education has a greater place in our lives and its QA deserves more attention that it could attract before. The development of QA in distance learning/e-learning can be enhanced by professional, transparent assistance provided to HEIs by evaluation and accreditation agencies. This can be achieved through a relation based on trust where the agencies are also monitored, registered and recognized by national and international stakeholders.

The accreditation and/or academic audits are either mandatory or voluntary in different countries and the agencies are governmental, quasi-governmental or independent institutions. Practices may change, however according to all approaches, quality agencies are important stakeholders, which governments keep an eye on, though the level of control and the means utilized to monitor their work may change (Lewis, 2016). Quality assurance agencies work with standards to evaluate students' learning outcomes. In addition to this, the penetration of ODL to all disciplines emphasizes the need for evaluation criteria developed specifically for open/distance/online/blended learning that requires the evaluation of ODL media utilized to reach the outcomes. Institutions apply either common standards for conventional and distance education or standards specific to distance education. However, behind is a common rationale for the adoption of quality frameworks; that is ensuring accountability and improving the quality of services. This sensitivity vis-a-vis social engagement and transparency required for this, also necessitates a thorough examination of the ODL QA methods and their integration to the accepted standards in both national and international contexts. AUDAK in these circumstances aims to be among best-practices in the provision of QA standards specific to open and distance education, assist distance teaching institutions on their path to quality and at the same time continue with its own improvement as an agency.

\section{BIODATA and CONTACT ADDRESSES of AUTHORS}

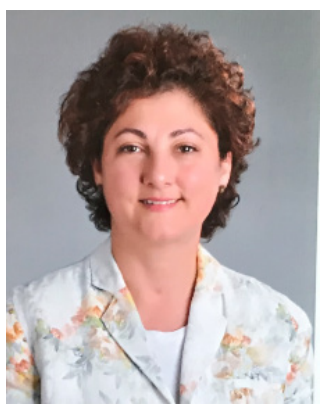

Dr. Elif TOPRAK is an Associate Professor of Applied Communications at Open Education Faculty, Anadolu University, Eskisehir, in Turkey. She received her BSc, MSc and PhD degrees in the discipline of International Relations (IR), from Middle East Technical University, Bilkent University and Uludag University respectively. She teaches IR Theory, Globalization and International Distance Education, International Communication and Public Diplomacy courses. Her research interests are international cooperation and regimes, intercultural communication, transnational higher education, administration in open and distance education, quality assurance and accreditation in open and distance learning.

\section{ElifTOPRAK}

Department of Distance Education, Open Education Faculty

Address: Anadolu University, Open Education Faculty, 26470, Eskisehir, Turkey

Phone: +90 2223350580 - 2456

E-mail: etoprak1@anadolu.edu.tr 


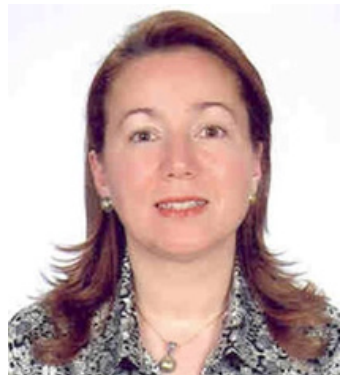

Dr. Asuman Nurhan SAKAR is an Assistant Professor of Management at Open Education Faculty, Anadolu University, Eskisehir, in Turkey. She received her Ph.D. in Management from Anadolu University, IMBA from the, Baldwin Wallace College-USA and BEc in Economics from Anadolu University. She teaches, Management \& Organization and Reputation Management. Her academic interest areas are management of higher education institutions, managerial issues of open and distance education institutions, quality assurance and accreditation of higher education institutions.

Asuman Nurhan SAKAR

Department of Economic and Administrative Programs, Open Education Faculty Address: Anadolu University, Open Education Faculty, 26470, Eskisehir, Turkey Phone: +902223350580-2767

E-mail: nsakar@anadolu.edu.tr

\section{REFERENCES}

Abdous, M. (2009). E-learning quality assurance: a process-oriented lifecycle model. Quality Assurance in Education, 17(3), 281-295.

Angolia, M. G. \& Pagliari, L. R. (2016). Factors for successful evolution and sustainability of quality distance education. Quality in Higher Education, 19(3), Fall 2016.

Belawati, T. \& A. Zuhairi (2007). The practice of a quality assurance system in open and distance learning: A case study at Universitas Terbuka Indonesia (The Indonesia Open University). The International Review of Research in Open and Distributed Learning, 8(1), March 2007, ISSN: 1492-3831.

Benson, A. D. (2003). Dimensions of quality in online degree programs. The American Journal of Distance Education, 17(3), 145-159. Retrieved from https://doi.org/10.1207/S15389286AJDE1703_2

Campbell, C. \& van der Wende, M. (2000). International initiatives and trends in quality assurance for European Higher Education. Exploratory Trend Report-The European Network for Quality Assurance in Higher Education, Helsinki. ISBN 951-98680-0-3.

Eaton, J. S. (2000). Core academic values, quality and regional accreditation: The challenge of distance learning. Council for Accreditation Higher Education (CHEA) Report. USA: Washington, DC.

ENQA. (2015). Standards and guidelines for quality assurance in the European Higher Education Area (ESG). Brussels, Belgium. ISBN: 978-9-08-168672-3 Retrieved from http://www.enqa.eu/index.php/ home/esg/

EQUIP. Comparative analysis of the ESG 2015 and ESG 2005. Retrieved from https://enqa.eu/index.php/ publications/papers-reports/associated-reports/

Esfijani, A. (2018). Measuring quality in online education: A meta-synthesis. American Journal of Distance Education, 32(1), 57-73. Retrieved from https://doi.org/10.1080/08923647.2018.1417658

Frydenberg, J. (2002). Quality standards in e-learning: A matrix of analysis. International Review of Research in Open and Distance Learning, 3(2), 1-15.

Gaebel, M., Kupriyanova, v., Morais, R. \& Colucci, E. (2014). E-learning in European higher education institutions. EUA Publications, Brussels, Belgium.

Gao, Y. \& Legon, R. (2015). Internationalizing Quality Matters ${ }^{\mathrm{TM}}$ : The China case. American Journal of Distance Education, 29(3), 210-219. Retrieved from https://doi.org/10.1080/08923647.2015.1 059077.

Grifoll, J., Huertas, E., Prades, A., Rodriguez, S., Rubin, Y., Mulder, F. \& Ossiannilsson, E. (2010). Quality assurance of e-learning. ENQA Workshop Report 14, Helsinki, Finland. ISBN 978-952-5539-52-3. 
Harvey, L. \& Williams, J. (2010). Fifteen years of Quality in Higher Education (Part Two). Quality in Higher Education, 16(2), 81-113. Retrieved from https://doi.org/10.1080/13538322.2010.485722

Huertas, E., Biscan, I., Ejsing, C., Kerber, L., Kozlowska, L., Marcos Ortega, S., Lauri, L., Risse, M., Schorg, K. \& Seppman, G. (2018). Considerations for quality assurance of e-learning provision. ENQA Occasional Papers 26, Brussels, Belgium. ISBN 978-952-5539-88-2.

Kanwar, A., Mohee, R., Carr, A., Ortlieb, K. \& Sukon, K. (2019). A neo-institutionalist approach to understanding drivers of quality assurance in ODL: The case of the Open University of Mauritius. International Review of Research in Open and Distributed Learning, 20(4), 79-98.

Kocdar, S. (2011). Accreditation of distance education programs in Turkey based on expert opinions (Unpublished $\mathrm{PhD}$. thesis) Anadolu University, Graduate School of Social Sciences, Department of Distance Education, Eskisehir, Turkey.

Krause, J., Portolese Dias, L. \& Schedler, C. (2015). Competency-based education: A framework for measuring quality courses. Online Journal of Distance Learning Administration, 18(1), Spring 2015.

Lewis, R. (2016). Principle 6: Quality and quality assurance bodies. The CIQG International Quality Principles: Toward A Shared Understanding of Quality. Uvalic-Trumbic S. (Ed). CIQG Publication Series. Retrieved from http://www.chea.org/userfiles/PDFs/Principles_Papers_Complete_web. pdf

Manatos, M. J. \& Huisman J. (2020). The use of the European Standards and Guidelines by national accreditation agencies and local review panels. Quality in Higher Education, 26(1), 48-65. Retrieved from https://doi.org/10.1080/13538322.2020.1728835.

Masoumi, D. \& Lindstrom, B. (2012). Quality in e-learning: A framework for promoting and assuring quality in virtual institutions. Journal of Computer Assisted Learning, 28, Special Issue, 27-41.

Oliver, R. (2005). Quality assurance and e-learning: Blue skies and pragmatism. ALT-J, 13(3), 173-187. Retrieved from https://doi.org/10.1080/09687760500376389.

Ossiannilsson, E. \& Landgren L. (2012). Quality in e-learning-a conceptual framework based on experiences from three international benchmarking projects. Journal of Computer Assisted Learning, 28, Special Issue, $42-51$.

Pawlowski, J. M. (2007). The quality adaptation model: Adaptation and adoption of the quality standard ISO/IEC 19796-1 for learning, education and training. Educational Technology \& Society, 10(2), 3-16.

Pond, W. K. (2002). Distributed education in the $21^{\text {st }}$ century: Implications for quality assurance. Online Journal of Distance Learning Administration, 5(2), Summer 2002.

Popovich, C. J. \& Neel R. E. (2005). Characteristics of distance education programs at accredited business schools. The American Journal of Distance Education, 19(4), 229-240.

Saba, F. (2012). A systems approach to the future of distance education in colleges and universities: Research, development, and implementation. Continuing Higher Education Review, vol. 76.

Shattuck, K. (2017). Building a scalable bridge while assuring quality. American Journal of Distance Education, 31(3), 151-153. Retrieved from: https://doi.org/10.1080/08923647.2017.1337930

Sixl-Daniell, K., Williams, J. B., Wong, A. (2006). A quality assurance framework for recruiting, training (and retaining) virtual adjunct faculty. Online Journal of Distance Learning Administration, 9(1), Spring 2006.

Tomas, C. \& Kelo, M. (2020). ESG 2015-2018 ENQA agency reports: Thematic analysis. ENQA Occasional Paper 28, Brussles, Belgium. ISBN 978-952-5539-92-9.

Toprak E., A.N. Sakar. (2018). Cultural diversity and accreditation: A shared understanding of quality. In E. Toprak \& E. Genc Kumtepe (Eds) Supporting Multiculturalism in Open and Distance Learning Spaces, USA: IGI Global Publications. 
Vlachopoulos, D. (2016). Assuring quality in e-learning course design: The roadmap. International Review of Research in Open and Distributed Learning, 17(6), 183-205.

Zhang, W. \& Cheng, Y. L. (2012). Quality assurance in e-learning: PDPP evaluation model and its application. International Review of Research in Open and Distance Learning, 13(3), June 2012.

https:/enqa.eu/index.php/home/esg/

http://www.eua.be/policy-representation/higher-education-policies/the-european-higher-education-areaand-the-bologna-process

http://www.yodek.org.tr/download/yonetmelik_dl.pdf

http://www.yok.gov.tr/web/kalitekurulu/

http://yokak.gov.tr/akreditasyon-kuruluslari/tescil-suresi-devam-edenler

https://yokak.gov.tr/theqc-becomes-enqa-member-125

http://audak.org/tarihce/

https://www.yokak.gov.tr/hakkinda

https://www.yokak.gov.tr/theqc-becomes-enqa-member-125

https://www.yokak.gov.tr/akreditasyon-kuruluslari/ulusal-akreditasyon-kuruluslari

https://www.yokak.gov.tr/akreditasyon-kuruluslari/tescil-suresi-devam-edenler

https://yokak.gov.tr/akreditasyon-kuruluslari/ulusal-akreditasyon-kuruluslari

https://portal.yokak.gov.tr/makale/uzaktan-egitim-ve-kalite-guvence-sistemi/

http://audak.org/degerlendiriciler-ve-kurumlar-icin-belgeler/

https://e-xcellencelabel.eadtu.eu/

http://audak.org/wp-content/uploads/2019/04/AUDAK-Degerlendirme_Olcutleri_1.0-15.04.2019.pdf 